\title{
DURASI AKUSTIK PEMBELAJAR BAHASA ARAB DI MEDAN
}

\author{
Khoirul Jamil M. Yaman \\ Universitas Sumatera Utara \\ khairul_jamil@hotmail.com \\ Tengku Silvana Sinar \\ Universitas Sumatera Utara \\ tengkusilvana@usu.ac.id
}

\begin{abstract}
Abstrak
Penelitian ini menganalisis bunyi tuturan Bahasa Arab yang diujarkan oleh pembelajar Bahasa Arab melalui analisis durasi tuturan pada modus interogatif, deklaratif dan imperatif. Tujuan menganalisis durasi tuturan pada modus interogatif, deklaratif dan imperatif adalah untuk menemukan bunyi akustik tuturan oleh pembelajar Bahasa Arab dan menjelaskan faktor penyebab terjadinya durasi. Sumber data penelitian ini adalah enam tuturan Bahasa Arab yaitu dua tuturan dalam modus deklaratif, tiga tuturan dalam modus interogatif dan satu tututuran dalam modus imperatif yang dituturkan oleh empat penutur pembelajar Bahasa Arab. Kerangka teoritis Fonetik Akustik dan metode kualitatif dalam menganalisis durasi bunyi-bunyi setiap tuturan pada modus interogatif, deklaratif dan imperatif. Metode eksperimental digunakan dalam menganalisis bunyi tuturan Berdasarkan hasil analisis data, penelitian ini menemukan durasi penutur asli dalam menuturkan bunyi vokal rangkap, pembelajar tidak menuturkan vokal dengan bunyi yang panjang. Hal ini menunjukkan adanya sistem bunyi konsonan dan vokal Bahasa Arab berbeda dengan bahasa Indonesia dan sistem bunyi bahasa Indonesia tidak memiliki bunyi-buni vokal rangkap. Dari temuan ini disimpulkan bahwa perbedaan sistem bunyi mengakibatkan pembelajar Bahasa Arab mengujarkan bunyi-bunyi tidak pada titik artikulasi yang tepat. Untuk itu, pembelajar Bahasa Arab memerlukan penguasaan terhadap ilmu Aswat dan pelatihan terhadap pengucapan lafal Bahasa Arab secara artikulatoris. Penelitian ini menyarankan agar metode pembelajaran kemahiran lafal BA perlu ditingkatkan secara teknologi baru dan dengan menggunakan penutur asli.
\end{abstract}

Kata kunci: fonetik eksperimental, frekuensi, intensitas, durasi, metode praat

\begin{abstract}
This study analyzes the sound of Arabic speech uttered by Arabic learner through an analysis of the duration of the speech on the mode of interrogative, declarative and imperative. The purpose of analyzing the duration of the speech on the mode of interrogative, declarative and imperative is to find the sound of acoustic speech by learning Arabic and explain the causes of the duration. The data source of this research is six Arabic speech that two utterances in declarative mode, three utterances in the interrogative mode and single mode tututuran imperative that spoken by the four speakers of Arabic language learners. Acoustic Phonetics theoretical framework and qualitative methods in analyzing the duration of each speech sounds in the interrogative mode, declarative and imperative. The experimental method used in analyzing the sounds of speech Based on the analysis of data, the study found the duration of a native speaker in said double vowels, learners do not said long vowel with the sound. This shows the system consonant and vowels in Arabic is different from the Indonesian and Indonesian sound system does not have a double vowel sound-Buni. From these findings concluded that the difference in the sound system lead learner Arabic utter sounds not at the point of articulation of the right. For that, learners Arabic Aswat requires mastery of knowledge and training to the pronunciation of Arabic pronunciations in articulatory. This study suggests that the learning method pronunciation skills BA should be promoted in new technology and by using native speakers.
\end{abstract}

Keywords: Experimental fonetic, frequency, intencity, duration, praat mode 


\section{PENDAHULUAN}

Bahasa Arab (BA) di Indonesia dipelajari pada strata mulai dari sekolah dasar berbasis islam hingga perguruan tinggi swasta dan negeri. Namun apabila ujaran-ujaran pembelajar BA didengarkan secara fonetis, tuturan-tuturan BA masih belum tepat secara akustik tempat dan sifat makhrajnya. Padahal tekanan dan jeda dalam BA dapat mengubah makna kalimat, jika ingin mewujudkan kefasihan berBA dari segi percakapan dan bacaan serta pengembangan diri para mahasiswa dalam menghadapi dunia global ini. Sebagai contoh \# "kitābun \#adiOun jadidun" yang artinya buku yang modren كتاب / الحديث // جديد baru diujarkan sebagai

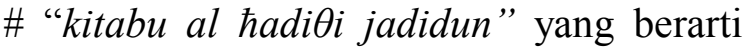
"buku mengenai hadis baru".

Pengucapan bunyi suprasegmental BA harus dibedakan dari durasi atau panjang pendeknya ketika bunyi itu diucapkan karena bunyi yang diucapkan itu mengandung masa ( mora). Secara akustik, durasi ujaran pada bunyi vokal BA lebih lama bila dibandingkan dengan bunyi konsosnan. Masing-masing bunyi konsonanpun mempunyai perbedaan durasi dalam ujaran. Hal ini disebabkan konsonan memiliki sifat (manner) bunyi yang berbeda dengan konsonan lain. Panjang-pendek bunyi di dalam BA dihasilkan dari bunyi vokal. Menurut durasi bunyi vokal BA ada dua yaitu bunyi pendek dan bunyi panjang sebagai berikut:

1) Bunyi pendek:

[a] dilambangkan dengan tanda (-disebut fathah ( (فتحة. Contoh [ka-ta-ba ] artinya; menulis.

[u] dilambangkan dengan tanda ( $(\stackrel{-}{-}$ disebut dhummah ( كثُبُّ3 ] Contoh -tu-bun ] artinya banyak buku.

[ i ] dilambangkan dengan tanda ( -$)$ disebut kasrah (كسرة) Contoh [i-bil] artinya seekor unta.

2) Bunyi panjang:

[ā] dilambangkan dengan tanda ( ( disebut alif ( (ألفContoh ] كتابki-tā-bun ] artinya sebuah buku.

[ $\overline{\mathrm{u}}]$ dilambangkan dengan tanda ( (

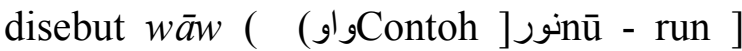
artinya cahaya.

[ 1 ] dilambangkan dengan tanda (ي ) disebut ya' (ياء). Contoh صديق [ṣa- dì qun ] artinya seorang teman laki-laki.

Pembelajar BA selalu mengabaikan durasi bunyi vokal panjang dan pendek dalam tataran kata, maka akibatnya terjadilah perubahan makna pada wacana yang diujarkan.

Bunyi vokal [ ā/a] ] Lb رma / țār] yang artinya 'bandara', sering diucapkan مطر / tar ] a yaitu 'hujan' dan bunyi vokal [ $\overline{1} / \mathrm{i}]$ ] باردā / rid] yang artinya 'dingin', diucapkan بريد[ba / rīd] yaitu 'kantor pos'.

Terjadinya perubahan makna akibat perbedaan durasi bunyi panjang diucapkan menjadi bunyi pendek acapkali terjadi juga pada ujaran kalimat verbal misalnya bunyi vokal [ $\bar{a} / \mathrm{a}]$ ] 


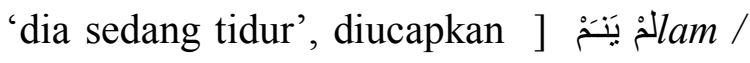
ya /nam] yaitu 'dia tidak tidur'; bunyi

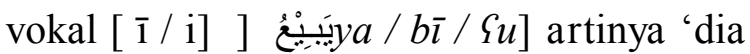
sedang berjualan', diucapkan لمَيَّ [lam / $y a / b i \varsigma$ ) artinya 'dia tidak berjualan'. Akibat mengujarkan bunyi vokal panjang menjadi bunyi pendek perubahan terjadi pada durasi bunyi vokal panjang yaitu [ '] terhubungnya dengan [ ] lam lang artinya menidakkan suatu perbuatan.

Untuk tujuan kefasihan dalam komunikasi BA, analisis dalam artikel ini mengambil data-data tuturan BA dari modus interogatif, deklaratif dan imperatif. Kajian ini menggunakan kajian fonetik akustik BA yaitu ilmu al așwāt agar faktorfaktor yang berhubungan ketidakfasihan mengujarkan BA dapat dijelaskan dari sudut Fonetik Eksperimental. Untuk itu dirumuskan satu masalah kajian "Bagaimanakah durasi tuturan pembelajar BA pada modus deklaratif dan imperatif?"

\section{KONSEP DAN KERANGKA TEORI}

\section{Konsep}

\section{Durasi}

Menurut Sugiyono (2003) durasi adalah waktu yang diperlukan untuk realisasi sebuah segmen yang diukur dalam satuan milidetik atau hentian sesaat yang lazim disebut jeda. Jika segmen itu kalimat, perbedaan waktu itu biasa disebut dengan tempo. Struktur temporal adalah seperangkat aturan yang menentukan pola durasi dalam tuturan. Dalam kajian ini ciri akustik tuturan BA dikaitkan dengan aspek bunyi vokal, konsonan dan lainya yang termasuk dalam kategori bunyi suprasegmental.

\section{Nada}

Beberapa konsep penting yang dipakai dalam mengkaji fonetik akustik adalah Nada Dasar (ND), Nada Final (NF), Puncak Nada (Fo) dan Julat Nada. Nada Dasar (ND) dapat digunakan untuk menyebut frekuensi dasar nada awal yang sesuai dengan sebuah alir nada atau sebuah kontur (Halim dalam Sugiyono 2003); Nada Final (NF) adalah nada yang terdapat pada akhir kontur intonasi secara keseluruhan; Puncak Nada digunakan untuk menyebut prominensi tertinggi dalam sebuah alir nada. Dalam kaitannya dengan Fo puncak nada adalah Fo tertinggi dalam sebuah alir nada, sedangkan lawan dari nada puncak adalah lembah; Julat Nada adalah rentang Fo dalam sebuah ujaran. Nada dasar ditentukan dengan menghitung selisih Fo tertinggi dan Fo terendah; Alir nada adalah komposisi nada-nada dalam domain konstituen pembentuk suara. Sebuah alir nada dapat digambarkan atas dasar perbandingan atau perubahan tinggi Fo.

\section{Kontur Intonasi}

Kontur Intonasi adalah perpaduan nada yang dapat memberi ciri melodik tuturan pada konteks modus, dan juga dapat membentuk struktur melodik sebuah tuturan. Sesungguhnya intonasi dianalisis 
sebagai kontur ada didalamnya variasi tingkat tinggi nada.

\section{Jeda}

Dalam BA jeda dinamakan al waqfu yaitu hentian sesaat antara segmen dengan segmen berikutnya dalam sebuah tuturan atau penghentian atau pemutusan suatu arus bunyi-bunyi suprasegmental ketika diujarkan oleh penutur yang menyebabkan sendi (juncture) dan merupakan tanda batas antara bentuk-bentuk linguistik baik dalam tataran kalimat, klausa, frase, kata, morfem dan silaba. Sendi luar dibedakan dengan adanya tanda:

( / ) menunjukkan penghentian antarkata dalam frase.

( // ) menunjukkan penghentian antarkata dalam klausa.

( \# ) menunjukkan antarkalimat wacana / paragraf.

\section{Teori}

\section{Ilmu Fonologi dan Fonetik}

Fonologi adalah cabang ilmu linguistik mengkaji sistem bunyi bahasa dan membahas cara-cara bunyi suatu bahasa digunakan sehingga dapat menghasilkan kata dan ujaran melalui alat ujar atau speech organs manusia sedangkan ilmu Fonetik mengkaji bunyi dari tiga dimensi yaitu fonetik akustik yang mengkaji ciriciri fisik dan bunyi bahasa, fonetik artikulatoris yang menyelidiki bunyi berdasarkan alat-alat ucap dalam artikulasi dan fonetik auditoris yang mengkaji bunyi berdasarkan pendengaran sebagai persepsi bahasa.

Menurut Samsuri (1978) fonetik akustik adalah cara arus bunyi yang keluar dari rongga mulut dan atau rongga hidung si pembicara yang merupakan gelombanggelombang bunyi udara yang didasarkan kepada penghasilan ilmu fisika dan matematika. Ridwan (2006) menyatakan fonetik akustik merupakan bagian dari kajian linguistik yang mengacu pada kajian unsur-unsur fisikal dari bunyi-bunyi ujaran, seperti tinggi nada, frekuensi, amplitudo dan lainnya.

Dalam linguistik BA ilmu fonetik dinamakan ilmu Al Așwāt (Bisr, 1980) yang mengkaji tentang bunyi pada saat diucapkan dan membawa pengaruh kepada pendengaran tanpa memperhatikan makna suara tersebut dalam bahasa tertentu.

Menurut Aziz ( 2009) ilmu Al Așwāt adalah; العلم الذي يدرس الصوت الانساني من وجهة (al Gilmu allað̄i yudarrisu al șauta al insaniya min wijhati al nazari al luyawiyah). Artinya; "suatu ilmu yang mempelajari bunyi suara manusia dari aspek kebahasaan”. Menurut Al Khauli (1982) Ilmu Al Aṣwāt adalah ilmu yang mempelajari tentang pembentukan, perpindahan dan penerimaan bunyi bahasa.

\section{Fonetik Akustik}

Dari penjelasan di atas, disimpulkan bahwa kajian fonetik akustik meneliti perbedaan tinggi nada (picht), keras atau lembut walaupun diucapkan dengan nada tinggi atau rendah dan gelombang suara 
sebagai peristiwa fisika atau fenomena alam yang membentuk hubungan antara pembicara dengan pendengar. karena bunyi -bunyi itu memilki kualitas sendiri-sendiri.

Gelombang-gelombang udara yang bergerak keluar menghasilkan gelombang suara dan akibat pergeseran molekulmolekul udara dapat mengakibatkan getaran. Bergeraknya molekul-molekul udara mendorong molekul udara yang lain dan seterusnya molekul yang lain lagi, sampai membentuk gelombang suara, untuk dapat meneliti secara mendalam bunyibunyi yang diujarkan maka kajian fonetik akustik mencakup tiga aspek penting yaitu frekuensi, intensitas dan durasi bunyi-bunyi (Bright, 1992).

Analisis BA pada artikel ini hanya difokuskan pada dua durasi modus tuturan yaitu tuturan deklaratif atau pernyataan dan imperative atau perintah.

\section{PEMBAHASAN}

Dalam kajian ini dipilih tiga tuturan target yang dijadikan dasar dalam pemerian kontur nada beserta pembuatan kalimat yang telah distilisasi. Keenam korpus dan kalimat yang dipilih dalam penelitian ini antara lain;

Tuturan deklaratif terdiri atas dua kalimat yaitu;

1) أكلت الأرز مع الدجاج في الغذاء

(akaltu al aruzza maSa aldajāji fì alyadāi )

artinya; saya sudah makan nasi dengan ayam pada siang hari.

2) يثرب الطفل كوبا من اللبن الصافي (yafrabu altiflu kūban min allabani alfāấ) artinya; anak itu minum secangkir susu murni.

Tuturan imperatif terdiri atas satu kalimat yaitu;

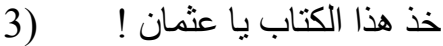

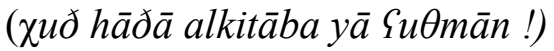

artinya; ambillah buku ini wahai Usman!.

\section{Durasi Modus Tuturan Dalam BA}

Modus Tuturan Deklaratif [akaltu alaruzza maYa al dajāji fĩ al yadäi ]

Total durasi modus tuturan deklaratif [akaltu al aruzza maSa al dajā ji fí al yadāi] yang lebih lama terdapat pada pembelajar BA (11110) mencapai 4.63 md, sedangkan total durasi yang diperoleh oleh penutur Arab (53110) lebih singkat yaitu; 2.33 md. Disimpulkan bahwa pembelajar BA mendominasi pada ketinggian total durasi, ini menunjukkan bahwa tekanan suara pembelajar BA saat mengujarkan kalimat deklaratif terlalu tinggi dan lambat bila dibandingkan dengan penutur Arab.

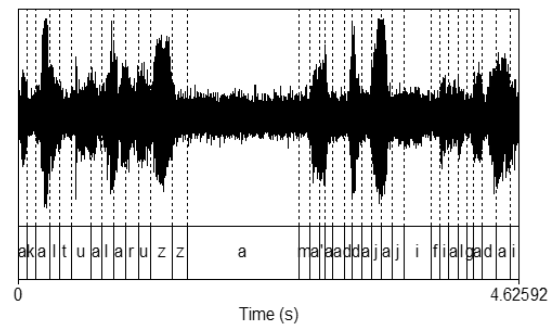

Gambar 1: Durasi pembelajar BA [akaltu alaruzza maSa al dajāji fí al radāi ]

Modus Tuturan Deklaratif [yafrabu al țiflu kūban min al labani al șăfī]

Total durasi modus tuturan deklaratif [yafrabu al tiflu kūban min al labani al șâfī 
yang lebih lama terdapat pada pembelajar BA (11120) mencapai 4.68 md, sedangkan total durasi yang diperoleh oleh penutur Arab (53120) lebih singkat daripada pembelajar BA mencapai 2.56 md. Disimpulkan bahwa pembelajar BA mendominasi pada ketinggian total durasi, ini menunjukkan bahwa tekanan suara pembelajar BA saat mengujarkan kalimat deklaratif terlalu tinggi dan lambat bila dibandingkan dengan penutur Arab

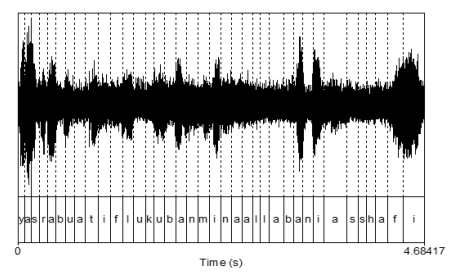

Gambar 2: Durasi pembelajar BA [yafrabu al țiflu kūban min al labani al șâfî $]$

\section{Modus Tuturan Imperatif $[\chi u ð h \bar{a} \partial \bar{a}$ al}



Total durasi modus tuturan imperatif

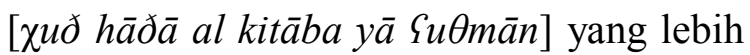
lama terdapat pada pembelajar BA (11310) mencapai $2.69 \mathrm{md}$, sedangkan total durasi penutur Arab (53310) lebih singkat daripada pembelajar BA mencapai 1.69 md. Disimpulkan bahwa pembelajar BA mendominasi pada ketinggian total durasi, ini menunjukkan bahwa tekanan suara pembelajar BA saat mengujarkan kalimat imperatif terlalu tinggi dan lambat bila dibandingkan dengan penutur Arab.

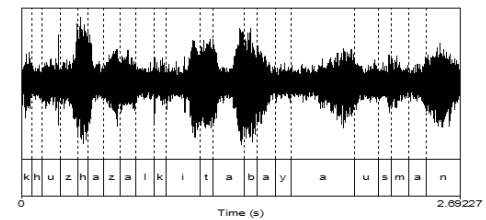

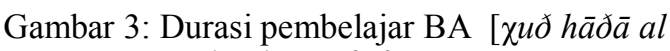
kitāba yā \&uӨmān]
Berdasarkan hasil analisis durasi tuturan Deklaratif [akaltu al aruzza maSa al dajā ji fi alyadāi] oleh pembelajar BA jika dibandingkan dengan penutur Arab telah ditemukan beberapa faktor yang menyebabkan terjadi perbedaan durasi. Faktor tersebut dapat diuraikan sebagai berikut:

Bunyi vokal dari segi panjang dan pendek di dalam BA dibagi kepada dua macam. Pertama, bunyi vokal pendek dilambangkan dengan $[$. [ - - $\stackrel{-}{-}$ Kedua, bunyi vokal panjang dilambangkan dengan ( ISedangkan penutur bahasa Indonesia hanya memiliki bunyi vokal satu macam saja, yaitu bunyi vokal pendek. Pada kalimat deklaratif [akaltu al aruzza maSa al dajāji fì al yadāi ] terdapat bunyi vokal panjang [ $\overline{\mathrm{a}}$ ] yaitu pada kata [al dajāji], [al yadāi] dan [al șāfī] bunyi [ $\overline{1}$ ] pada kata [ fī ].

Dari analisis durasi tuturan Deklaratif [ yafrabu al țiflu kūban min al labani al șâfi ] ditemukan penutur pembelajar BA lebih lama bila dibandingkan dengan penutur Arab karena bunyi vokal panjang [ $\bar{u}$ ] pada kata [kūban]. Pembelajar BA tidak terlatih menggunakan bunyi vokal panjang baik dalam bentuk percakapan maupun dalam bentuk bacaan. Dengan adanya bunyi vokal panjang di dalam tuturan kalimat deklaratif ini, dapat mengakibatkan pembelajar BA mengalami kesulitan dalam menuturkannya, sehingga timbul perbedaan durasi temporal dengan penutur Arab di dalam kalimat deklaratif itu. Yakni durasi temporal tuturan kalimat 
deklaratif yang dituturkan oleh pembelajar BA lebih lama daripada penutur Arab.

Durasi penutur pembelajar BA lebih lama bila dibandingkan dengan penutur Arab dalam tuturan imperatif [ $\chi и \delta ~ h \bar{a} \partial \bar{a} a l$ kitāba yā \{uӨmān ]. Berdasarkan analisis di atas, ditemukan perbedaan durasi temporal yaitu pembelajar BA memiliki durasi temporal lebih lama daripada penutur Arab. Perbedaan durasi ini terjadi disebabkan adanya bunyi vokal panjang [ $\bar{a}]$ pada kata [hāoā ], [kitāba ], [yā] dan [ [uümān]. Selain perbedaan bunyi vokal yang menyebabkan timbulnya perbedaan ini, ada juga bunyi konsonan yaitu bunyi $[\chi]$ pada kata $[\chi u ð]$,

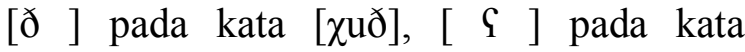

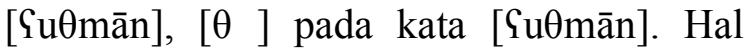
inilah yang menyebabkan terjadinya durasi temporal pembelajar BA lebih lama daripada penutur Arab.

\section{SIMPULAN}

Berdasarkan temuan dalam analisis modus tuturan BA berikut ini disimpulkan bahwa tuturan pembelajar BA pada Fakultas Agama Islam di Universitas Al Washliyah Medan pada modus deklaratif dan imperatif memiliki perbedaan bunyi dengan penutur model yaitu penutur Arab. Bunyi yang dimaksud adalah bunyi yang berkaitan dengan struktur durasi.

Tuturan kalimat BA dipandang dari segi durasinya bahwa pembelajar BA belum memiliki tempo atau durasi yang tepat bila dibandingkan dengan penutur asli Arab karena di dalam bahasa Indonesia tidak mengenal bunyi vokal panjang dalam tutur kata, sehingga pembelajar selalu tidak tepat menuturkan kata BA dalam bentuk percakapan.

\section{UCAPAN TERIMA KASIH}

Penulis mengucapkan terima kasih kepada mitra bestari atas kritikan dan masukan yang membangun untuk perbaikan artikel ini.

\section{DAFTAR PUSTAKA}

Al Tawwaab, Ramadhan, 1999. Fušul Fî Fiqh Al Arabiyyah, Pustaka Al Khanji Cairo Egypt.

Al Abrasy, M. Atịyah, Al Mūjaz Fì Al suruq Al tarbawiyah, Al Fajjalah - Egypt.

Abadi, Al Fairuz .1987. Al Qãmīs Al Muhît Muassasah Al Risãlah Press, Beirut.

An̄̄s, Ibrahim 1999. Al Ashwat Al Lughawiyah, Al Anjelo Al Mishriyah, Cairo.

Al Islamiyah, Jami' ah Al Imam Muhammad bin Su'ud, Al Qira-ah wal Kitabah-

Silsilah Ta'lim Al Lughah Al 'Arabiyah: Saudi Arabia.

Al Sa'ran, Mahmud. 1997. Ilmu Al lugha Dar Al Fikri Al Arabi,Cairo.

Bright, William. 1992. International Encyclopedia of Linguistic. New York: Oxford University Press.

Basyar, Kamal. 2000. Ilmu Al aswat Dar Al garib, Cairo.

Chaiyanara, Paitoon 2007. Kepelbagaian Teori Fonologi, Singapore.

Chaer, Abdul. 1994. Linguistik Umum, Jakarta: Rineka Cipta.

Cohen, L.and Manion, L. 1994. Research Methods in Education. London: Routledge.

Hayward, Kartina 2000. Experimental Phonetics. London : Pearson Education Limited.

Kamaluddin, Hazim Ali, 1999. Dirasat fi Ilmi Al Aswat Maktaba Al adab, Cairo.

Lehiste, Ilse. 1970. Suprasegmentals. Cambridge: The MIT Press.

Masluh, Sa'ad. Dirasat Al Naqdiyah fi Al Lisaniyat Al Arabiyah Al Mu'asirah Alim Al Kutub, Cairo.

Nasution, Ahmad 2009. 'Ilmu Al-Ashwat AlArabiyah, Jakarta AMZAH.

Ridwan, T.A.R. 1999. Bahasa dan Kebahasaan. 
Medan: Universitas Sumatera Utara.

Ridwan, T.A.R 1997. A Contrastive Study Between Bahasa Indonesia and Australian English Phonetics and Orthography, Medan: USU.

Samsuri, 1971. Tjiri-tjiri Prosodi Kalimat Bahasa Indonesia, Malang: FKSS- IKIP Malang.

Siregar, Bahren Umar. 2000. "Fungsi Pragmatika Intonasi di Dalam Bahasa

Indonesia: Suatu Kajian Awal". Dalam Jurnal Linguistik Indonesia No.1.
Sugiyono, 2003. Fonetik, Jakarta Pusat Bahasa Departeman Pendidikan Nasional.

Sugiyono, 2003. Pemarkah Prosodik Kontras Deklaratif dan Interogateklaratif

dan Interogatif Bahasa Melayu Kutai (Disertasi) Depok:

PascasarDisertasi) Depok: Pascasarjana UI.

Syahin, Abdu Al Shabur, 1985. Dirasat Ilmu Al Aswat Al Mubarmajah Maktaba Al Syabab, Cairo. 